\title{
Deconstructing Milk Yield and Composition During Lactation Using Biologically Based Lactation Models
}

\author{
G. E. Pollott \\ Department of Agricultural Sciences, Imperial College London, \\ Wye, Ashford, Kent, TN25 5AH, UK
}

\begin{abstract}
A recently developed biological model of lactation described changes in daily milk yield throughout lactation as the result of 3 processes, secretory cell differentiation, cell death, and secretion rate per cell. This paper extends the model to describe the production of milk components (fat, protein, lactose, and water) throughout lactation by replacing milk secretion rate of the original model with the secretion rates of the four components. The milk component model approach was used to examine the relationship between milk yield and the major determinants of its production, using the secretion of milk components throughout lactation. Newly derived models were tested on 461 lactations from a single Holstein herd and used to estimate variability of secretion rates throughout lactation. Because the pattern of cell numbers throughout lactation is not precisely known, an alternative pattern of cell numbers was modeled and the concomitant change in secretion rates outlined. Fat secretion rate was the most variable, as measured by its weekly coefficient of variation throughout lactation. Secretion rates of lactose and water were nearly constant throughout lactation and highly correlated (0.94). Fat and protein secretion rates also were well correlated (0.53). The known biochemistry of milk component production related well to the secretion rate observations derived from the model. Lactose secretion rate and numbers of active secretory cells primarily determined daily milk yield.
\end{abstract}

(Key words: lactation curve, milk composition, milk yield)

\section{INTRODUCTION}

Milk is a mixture of fat, protein, lactose, vitamins, and minerals, either dissolved or suspended in water. Each component is either produced by the active secretory cells or is filtered through the epithelial cells in

Received February 25, 2004

Accepted March 29, 2004.

E-mail: g.pollott@imperial.ac.uk. the mammary gland during lactation, and the weight of each component produced per animal each day has been described by numerous authors (see Olori et al., 1997). The secretion rate of milk components is commonly described in relation to the whole udder. The actual secretion pattern of milk and its components per cell, throughout lactation, has not been clearly defined. In their review of mammary development and function, Knight et al. (1998) concluded that the decline in milk yield in late lactation paralleled the decline in secretory cell numbers and that secretory cell activity remained high throughout declining lactation. They also stated that secretory cells continued to be produced until around the peak of lactation. Patterns of secretion rate of milk components per cell are largely unknown due to the difficulty of measuring the number of active cells on any given day of lactation, or individual cell metabolism throughout lactation.

Milk production during lactation has been described in biological terms using a model comprising 3 functions to represent cell proliferation and differentiation, cell death (apoptosis), and secretion rate (Pollott, 2000). This "biological" approach to describe milk yield has been shown to accommodate the effects of changes in nutrition on milk yield during lactation and the effect of pregnancy on milk yield. It can also be used to calculate various characteristics of lactation curves, such as the day and extent of peak yield, rates of increase, and decline in milk yield at specific points in the lactation and total milk yield. Use of this approach has been compared with a range of empirical and biological models in cattle (Pollott, 2000) and sheep (Pollott and Gootwine, 2000). Using dairy sheep as an example, factors affecting both the parameters of the model and calculated values have been investigated by Gootwine and Pollott (2000). The genetics of these parameters, and calculated values, and the relationships between them have been described by Pollott and Gootwine (2001).

The objective of this paper was to derive suitable expressions to describe the production of milk constituents throughout lactation using the model of Pollott (2000), and to investigate some factors that influence characteristics of the lactation curves for these various components. 


\section{MATERIALS AND METHODS}

\section{Developing Lactation Curve Functions for Milk Components}

The multiplicative model, for describing changes in milk yield $(\mathrm{M} ; \mathrm{kg} / \mathrm{d})$ during lactation using the biologically-based approach of Pollott (2000), was M = (NDPC $\times$ PR) $\mathrm{S}_{\mathrm{M}}$. In this model, NDPC was the number of differentiated parenchyma cells and PR was the proportion of differentiated cells still active on any day of lactation. The term $S_{M}$ was the milk offtake rate on any given day of lactation, more loosely called the secretion rate of the active parenchyma cells, in kilograms per cell, per day. The secretion rate term was based on comments by Knight et al. (1998) and also on the fact that milk secretion starts from zero at or around $d 1$ of lactation (Pollott, 2000), reaches a maximal value, and then remains at that value throughout lactation. However, this is not a clearly defined relationship (Knight et al., 1998). Modeling work by Vetharaniam et al. (2003) suggested that secretion rate may be highly dependent on energy availability throughout lactation, and thus follows a different pattern for each animal in relation to the range of factors that cause energy supply to the udder to vary. No reports exist from extensive measurements of cell numbers or secretion rate throughout lactation and the exact pattern of these key determinants of milk production. Thus, the work reported herein is based on assumptions about the pattern of cell numbers and secretion rates throughout lactation. Although this is somewhat unsatisfactory, the approach outlined herein will have wide application once such measurements become possible.

Summarizing the description of daily milk yield in full gives:

$$
\begin{gathered}
M_{t}=\left[N /\left(1+\frac{1-P_{0}}{P_{0}} e^{-G t}\right)\right] \times\left[1+Q_{0}-\{1 /(1\right. \\
\left.\left.\left.+\frac{1-Q_{0}}{Q_{0}} e^{-D t}\right)\right\}\right] \times\left[S_{a}\left(1-e^{-S_{b} t}\right)\right] \\
{[\mathrm{NDPC}][\mathrm{PR}]\left[\mathrm{S}_{\mathrm{M}}\right]}
\end{gathered}
$$

where $M_{t}$ is milk production in $\mathrm{kg} / \mathrm{d}$ on day $t$ of lactation, $N=$ total number of parenchyma cells that become active during lactation, $P_{0}=$ proportion of $N$ present at the start of lactation, $G=$ the relative growth rate in active cell numbers $(G>0), t=$ day of lactation, $Q_{0}=$ proportion of $N$ dead at start of lactation, $D=$ the relative death rate of cells $(D>0), S_{a}=$ the maximum secretion rate of milk (kg/cell per day), and $S_{b}=$ the relative rate of change in milk secretion rate $\left(S_{b}>0\right)$.

This form of the model sets the rate of apoptosis at parturition to zero by subtracting $Q_{0}$ from the apoptosis term, PR (Pollott, 2000; appendix). This is an empirical modification to the original model that may be abandoned when levels of apoptosis throughout lactation have been better characterized.

This model can be used for any milk constituent by using the weight of the component produced per day as the dependent variable. Commonly, the available weights are fat, protein, lactose, water, and total solids, all measured in kilograms per day, but any measurable milk constituent, including ash, minerals, and vitamins, could also be used. For any given lactation, the only term in model 1 to differ among the different milk constituents (and milk yield) is the last expression for milk offtake rate $\left(\mathrm{S}_{\mathrm{M}}\right)$, because the first 2 terms relate to cell differentiation and apoptosis of the same cells that are secreting all the components. If the same cell differentiation and death curves are fitted to all 5 milk constituent lactation curves, then the difference among them and the actual component weights per day is the secretion rate of that component on the test-day. For example, weight of fat ( $\mathrm{F} ; \mathrm{kg} / \mathrm{day})$

$$
\mathrm{F}=(\mathrm{NDPC} \times \mathrm{PR}) \times \mathrm{S}_{\mathrm{F}}
$$

where $S_{F}(\mathrm{~kg} / \mathrm{cell}$ per day) is the weight of fat secreted by the average cell on any given day. Thus $S_{F}=F /$ $(\mathrm{NDPC} \times \mathrm{PR})$, and most of the parameters on the righthand side of this relationship, using the full model (model 1), can be derived from an analysis of any suitable lactation curve. Exceptions to this are the total number of parenchyma cells that become active during lactation $(\mathrm{N})$, which cannot be derived from the commonly collected farm data, and fat weight, which is a measured value.

Because commonly available farm records comprise test-day milk yields and component proportions (say FP for fat proportion), it may be better to think of $\mathrm{S}_{\mathrm{F}}$ using these values. Thus by rewriting model 2 using FP then:

$$
\mathrm{F}=(\mathrm{NDPC} \times \mathrm{PR}) \times \mathrm{S}_{\mathrm{M}} \times \mathrm{FP}
$$

Model 3 is model 1, describing the curve for milk production, multiplied by the fat proportion measured on a given day.

Substituting model 3 in model 2 and rearranging the terms gives:

$$
\mathrm{S}_{\mathrm{F}}=\mathrm{FP} \times \mathrm{S}_{\mathrm{M}}
$$

This expression describes the daily quantity of fat produced by the average cell. The pattern of fat secretion per cell throughout lactation differs from the pattern of fat secretion of the whole udder because of possi- 
ble changes in the number of active cells during lactation. Similar expressions for protein, lactose, total solids, and water may be derived by substituting the proportions of these components for fat in models 2,3 , and 4.

Alternatively, it is possible to describe milk yield in terms of the number of productive cells and the sum of the secretions of the components:

$$
\mathrm{M}=(\mathrm{NDPC} \times \mathrm{PR}) \times\left(\mathrm{S}_{\mathrm{F}}+\mathrm{S}_{\mathrm{P}}+\mathrm{S}_{\mathrm{L}}+\mathrm{S}_{\mathrm{W}}\right)
$$

where the subscripts $\mathrm{P}, \mathrm{L}$, and $\mathrm{W}$ refer to the secretion rate of protein, lactose, and water (plus vitamins, minerals, and ash), respectively. This form of the model describes milk yield as a product of several biological processes, cell production, differentiation, and death, and the factors that determine fat, protein, lactose, and water secretion. If these different biological processes are controlled independently of each other, then milk yield results from the sum of a variable set of independent factors. If it were possible to characterize a lactation in this way, then a more complete description of milk yield would be obtained and a more meaningful way of considering its modification may be achievable.

\section{Records Used to Test the Biological Model on Milk Component Weights}

The lactation records used in the current study were described previously by Olori et al. (1997, 1999a,b). Briefly, the cows were part of the multiple-ovulation and embryo-transfer herd owned by Genus Ltd. These cows were kept at Genus Ltd.'s Bays Leap Farm, Northumberland, UK. Establishment and management of the herd were described by Strathie and McGuirk (1995). Cows were housed indoors throughout the year and milked thrice daily. They were fed a TMR all year. Milk production from individual cows was recorded at each milking and weekly test-day yields were recorded along with percentages of fat, protein, and lactose.

First-lactation records, used in this analysis, comprised daily milk yields and weekly composition measurements collected from 488 cows from wk 2 to 44 of lactation. The original dataset comprised 20,095 testday records, representing calvings between July 1990 and December 1994. A number of factors that may affect milk yield were recorded, including age at first calving, day of each test-day record, pregnancy status, time of conception, calving date, and week of lactation. Month of calving and month of production were grouped by 2 mo increments for these analyses, resulting in 6 groups per calendar year (Olori et al., 1997).

Weekly test-day records were used in these analyses. Records available comprised test-day milk yield $(\mathrm{kg})$ and proportions of fat, protein, and lactose in test-day milk samples. Weights $(\mathrm{kg})$ of fat, protein, and lactose produced per day were calculated using the appropriate proportion value and test-day milk yield. Total solids were calculated as the sum of the three component weights (fat + protein + lactose); the weight of water produced daily was calculated as milk weight minus total solids; and the proportion of water was calculated as 1 minus the sum of fat, protein, and lactose proportions. Thus, water estimates included the small amount of ash, minerals, and vitamins produced in milk, typically about 0.009 by weight (see Tow, 1984). In these analyses, the week of lactation was used as the time variable ( $t$ in model 1$)$.

\section{Overall Production of Milk Components}

To derive overall production curves for the 6 weight traits (milk, fat, protein, lactose, total solids, and water), a least squares analyses was carried out to derive the weekly test-day means free of the effects of cow, year, month of production, and pregnancy status. Model 6 was fitted to 17,862 test-day records using the GLM procedure of SAS (SAS Inst., Inc., Cary, NC):

$$
\begin{aligned}
y_{i j k l m}= & \mu+w_{i}+m_{j}+p_{k}+c_{l}+w_{i} m_{j} \\
& +w_{i} p_{k}+m_{j} p_{k}+e_{i j k l m}
\end{aligned}
$$

where $y_{i j k l m}$ was the appropriate test-day weight (milk, fat, protein, lactose, water, or total solids) from the $l$ th cow $(c ; l=1$ to 488$)$ in the $i$ th wk of lactation $(w ; i=2$ to 44$)$ and $j$ th $\mathrm{yr} / \mathrm{mo}$ of production $(m ; j=1$ to 27$)$ during the $k$ th month of pregnancy ( $p ; k=0$ to 8), and $e_{i j k l m}$ was the randomly distributed error term. The terms $w_{i} m_{j}, w_{i} p_{k}$, and $m_{i} p_{k}$ were the interactions involving week of lactation, month of production, and month of pregnancy. Only records with complete sets of information for all traits and class variables were used in these analyses. The proportion of the overall variance of a trait accounted for by each effect in model 6 was calculated by fitting a reduced model, omitting the effect of interest. The proportional reduction in the residual sum of squares between the full and reduced models used was then calculated.

Least square means for week of lactation (plus an extrapolated estimate for wk 1) were used to describe the production of each of the 6 traits throughout lactation. This produced 6 lactation curves, one each for milk, fat, protein, lactose, total solids, and water weight. The multiplicative model of Pollott (2000) was then fitted to these 6 curves using an iterative, nonlinear, curvefitting procedure (NLIN in SAS). This modified model 1 took the form: 


$$
\begin{gathered}
M_{t}=\left[M S /\left(1+\frac{1-P_{0}}{P_{0}} e^{-G t}\right)\right] \times\left[1+Q_{0}\right. \\
\left.-\left\{1 /\left(1+\frac{1-Q_{0}}{Q_{0}} e^{-D t}\right)\right\}\right] \times\left[1-e^{-S_{b} t}\right]
\end{gathered}
$$

where $M S$ was the maximal secretion potential of the udder. The term $M S(\mathrm{~kg} / \mathrm{d})$ is a composite of the number of parenchyma cells that become active during lactation $(N)$, and the maximal secretion rate of cells $\left(S_{a}\right)$ (i.e., $M S=N \times S_{a}$ ). As Pollott (2000) pointed out, it is not possible to separate these 2 components using commonly collected farm records. When applying this model to the 6 weight traits, the only difference among them was in the secretion rate term, which was calculated in its composite form $M S$, and $S_{b}$. The term for milk yield $(M)$ was replaced by fat, protein, lactose, water, and total solids weight in model 7 to derive the other 5 lactation curves. This approach was used to investigate the differences in the lactation curves of milk and its 5 components.

The parameters of each curve were estimated using an iterative least square method, and the computational strategy of Marquardt (SAS, 1989) was used to find the "best fit" solution. The best fit solution was obtained for each curve when there was a $<10^{-6}$ difference between the error sums of squares in successive iterations.

Various characteristics of these 6 lactation curves (milk, fat, protein, lactose, water, and total solids) were calculated from the curve parameters using the methods described by Pollott (2000). These included peak yield, day of lactation on which peak occurred, calculated total milk yield to $\mathrm{d} 305$ of lactation, rate of increase in milk production midway between the start and peak of lactation, and rate of decline in milk yield midway between peak and d 305 of lactation.

\section{Secretion Rate of Milk Components}

Model 4 indicated that the different milk components are produced to different patterns depending on the combination of milk secretion and component proportion throughout lactation. Use of model 1 implied that the only term that should differ between the lactation curves of different components is the last one, describing the change in secretion rate during lactation. Model 8 was used to investigate the pattern of secretion rates for fat, protein lactose, total solids, and water:

$$
\begin{gathered}
S_{F t}=(F / N) /\left[1 /\left(1+\frac{1-P_{0}}{P_{0}} e^{-G t}\right)\right] \times\left[1+Q_{0}\right. \\
\left.-\left\{1 /\left(1+\frac{1-Q_{0}}{Q_{0}} e^{-D t}\right)\right\}\right]
\end{gathered}
$$

The values of $G, P_{0}, D$, and $Q_{0}$ were derived by fitting model 7 to the total milk weight weekly least square means (derived as described above). The 4 parameter values were then substituted in model 8 for each of the milk components. Model 8, an expansion of model 2, shows the calculation for fat secretion rate. Secretion rates of all other components were calculated by using the relevant values of protein, lactose, total solids, and water weight in place of $F$ using the least square weekly mean values (derived as described above). Results derived were the likely pattern of fat secretion throughout lactation, assuming $\mathrm{N}=2.8 \times 10^{10}$ (Vetharaniam et al., 2003) active cells that followed the pattern described by the overall cell production and apoptosis curves. Should it become possible in the future to measure or estimate $\mathrm{N}$, then by using the actual value for $\mathrm{N}$ in model 8 , the pattern of secretion rate values throughout lactation would remain the same, but the values would vary depending on the number of cells.

\section{Individual Cow Lactations-Milk Yield}

Lactation information from 461 first-lactation cows was used to investigate the production patterns of milk using the models outlined above. These cows had more than 15 weekly test-day records available for analysis after removal of information from test-day records, more than 2 standard deviations different from the previous week's record. This eliminated misrecorded data or records from mastitic cows from the analysis. Data were adjusted for month of production and stage of pregnancy using least square means derived from model 6 described previously.

$$
M_{t}=\left[M S /\left(1+\frac{1-P_{0}}{P_{0}} e^{-G t}\right)\right] \times\left[2-e^{D t}\right]
$$

Model 9 was fitted to all lactations using the iterative least square method described above. This model combines setting apoptosis to zero at parturition with the reduced form of the apoptosis curve (Pollott, 2000).

\section{Individual Cow Lactations-Component Traits}

Weekly secretion rates of the milk components were calculated using model 4 for each of the 461 lactations. Weekly milk offtake rate $\left(S_{M}\right)$ was derived for each lactation using the maximal secretion potential of the udder (MS) value derived from the model 9 analyses, described above, divided by $\mathrm{N}=2.8 \times 10^{10}$. These weekly component secretion rate values were thus derived assuming a constant rate of milk secretion throughout lactation. An alternative interpretation is to say that all daily changes in milk production are because of 


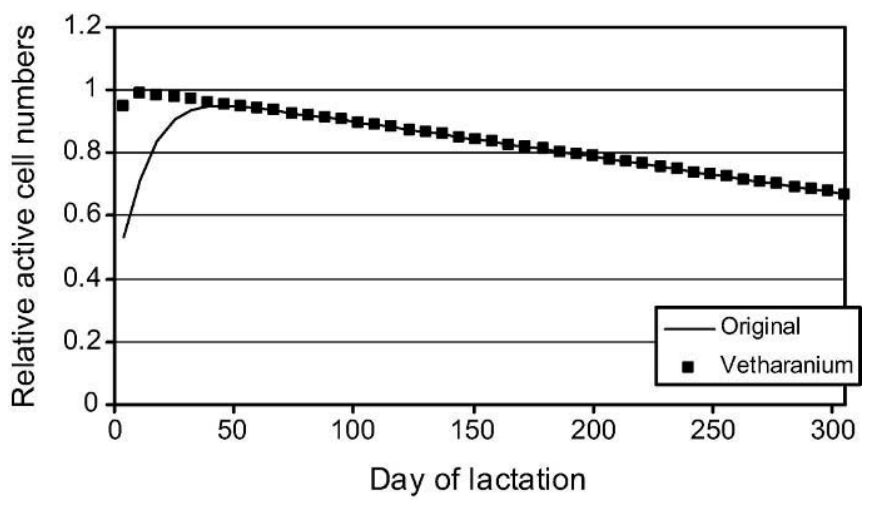

Figure 1. Two patterns of active cell numbers used to derive secretion rates in this study, one based on Pollott (2000) and the other based on Vetharaniam et al. (2003).

changes in active secretory cell numbers, a balance between cell production and death by apoptosis. If new physiological research shows milk secretion to have a different pattern, then the relativities between the different secretion rates will remain the same, but the actual secretion rate pattern of each component will differ in line with the new secretion rate pattern. These weekly component values were then analyzed in a GLM analysis using model 6 to see which factors had a significant influence on secretion rate of each component. Least square means for week of lactation and pregnancy were investigated to determine patterns of component secretion during lactation and effects of pregnancy on component secretion.

Weekly secretion rates for each milk component, for each cow, were investigated to explore the relationships among them. Correlations between secretion rate traits were calculated using residual variances and covariances derived from multiple analyses of variance (MANOVA option in GLM procedure of SAS) of all the traits, using model 6. Overall correlations were derived by fitting no fixed effects in the model. Within-cow correla- tions were derived by fitting cow as the only effect in the model. A further analysis was carried out fitting week of lactation and cow to detect the effect of removing week of lactation on correlations between various secretion rate values.

Weekly coefficients of variation for the 4 secretion rate traits (fat, protein, lactose, and water) were calculated to see how their variability changed throughout lactation.

\section{Investigating Alternative Patterns of Milk Secretion}

The pattern of milk secretion (or active cell numbers) used so far is largely unknown, but was based on comments by Knight et al. (1998). If alternative patterns of milk secretion (or active cell numbers) become apparent, then relative secretion rate patterns derived herein will change. For example, Vetharaniam et al. (2003) suggested a different rate of development of cell numbers during early lactation, using mammary gland modeling studies. The difference between the 2 patterns of cell numbers is shown in Figure 1. This "new" pattern was used to calculate secretion rates for cells from the overall weekly milk component production curve values derived from the least square analysis described above using model 2.

\section{RESULTS}

\section{Factors Affecting Test-Day Yields}

Results of fitting the effects of cow, month of production, week of lactation, and month of gestation to the 20,095 test-day records of the 6 milk component weight traits are summarized in Table 1, with the associated means, standard deviations, and coefficients of variation. No first-order interactions were detected $(P<0.05)$. Milk weight was $29.2 \mathrm{~kg} / \mathrm{d}$ on average, and comprised $1.12 \mathrm{~kg} / \mathrm{d}$ of fat, $0.99 \mathrm{~kg} / \mathrm{d}$ of protein, $1.43 \mathrm{~kg} / \mathrm{d}$ of lactose, and $25.7 \mathrm{~kg} / \mathrm{d}$ of water (plus ash, minerals, vitamins,

Table 1. Means, standard deviations, coefficients of variation, and proportions of variation accounted for by fixed effects used in a least square analysis of the 20,095 test-day records for the 6 milk weight traits.

\begin{tabular}{lcccccc}
\hline & $\begin{array}{l}\text { Milk } \\
\text { weight }\end{array}$ & $\begin{array}{l}\text { Fat } \\
\text { weight }\end{array}$ & $\begin{array}{l}\text { Protein } \\
\text { weight }\end{array}$ & $\begin{array}{l}\text { Lactose } \\
\text { weight }\end{array}$ & $\begin{array}{l}\text { Water } \\
\text { weight }\end{array}$ & $\begin{array}{l}\text { Total solids } \\
\text { weight }\end{array}$ \\
\hline Mean, kg/d & 29.2 & 1.12 & 0.994 & 1.43 & 25.7 & 3.54 \\
$\mathrm{SD}, \mathrm{kg}$ & 5.98 & 0.216 & 0.181 & 0.304 & 5.35 & 0.653 \\
$\mathrm{CV}, \%$ & 20.5 & 19.3 & 18.2 & 21.3 & 20.8 & 18.4 \\
$\mathrm{R}^{2}$ & 0.76 & 0.58 & 0.67 & 0.76 & 0.76 & 0.70 \\
Proportion of variance explained by the effect & $0.45^{* * *}$ & $0.36^{* * *}$ & $0.42^{* * *}$ & $0.42^{* * *}$ & $0.46^{* * *}$ & $0.41^{* * *}$ \\
Cow & $0.02^{* * *}$ & $0.02^{* * * *}$ & $0.05^{* * *}$ & $0.03^{* * *}$ & $0.02^{* * *}$ & $0.03^{* * * *}$ \\
Month of production & $0.07^{* * *}$ & $0.01^{* * * *}$ & $0.04^{* * *}$ & $0.09^{* * *}$ & $0.07^{* * *}$ & $0.05^{* * *}$ \\
Lactation week & $0.001^{* * *}$ & $0.001^{* * *}$ & $0.002^{* * *}$ & $0.001^{* * *}$ & $0.001^{* * *}$ & $0.001^{* * *}$ \\
\hline
\end{tabular}

$* * * P<0.001$ 

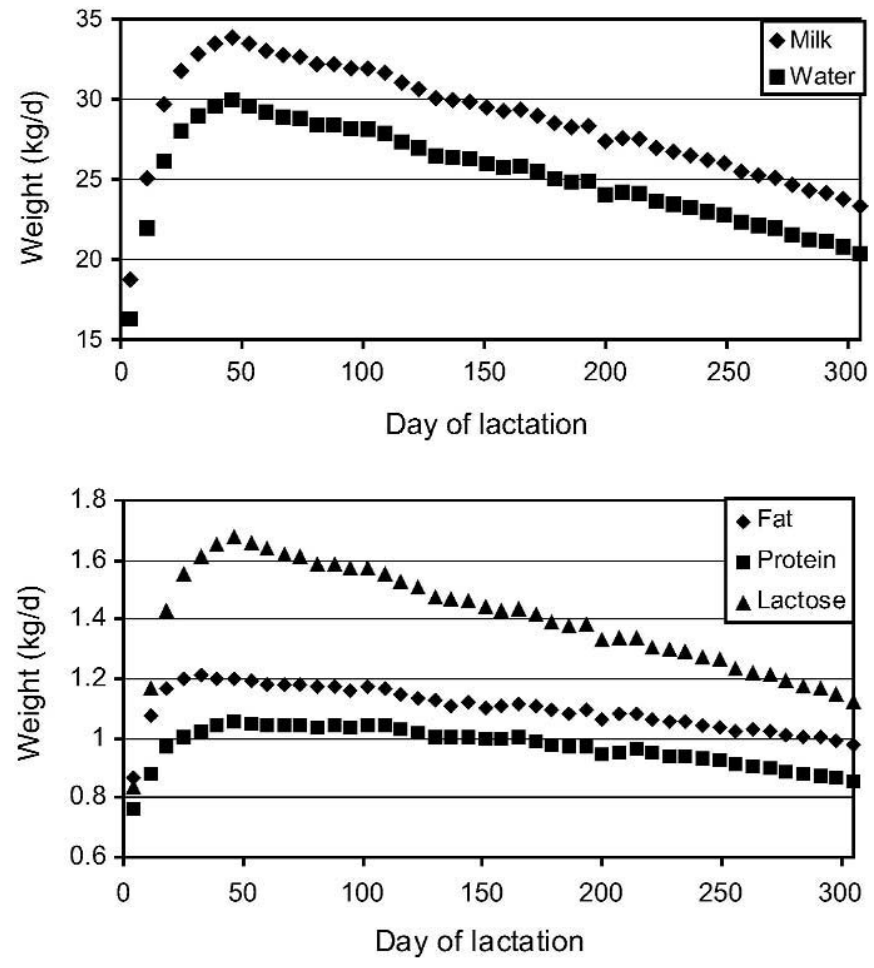

Figure 2. Lactation curves for milk and constituent weights de-

etc.). Total solids produced per day was $3.54 \mathrm{~kg}$. The model fitted to all traits accounted for between 58 (fat) and $76 \%$ (milk, lactose, and water) of the variance in the traits, as shown by the coefficient of determination $\left(\mathrm{R}^{2}\right)$. All 4 effects influenced the 6 weight traits $(P<$ 0.001 ). Variation associated with individual cows contributed most to the variation in test-day yields of all traits (36.0\% for fat weight to $45.8 \%$ for water weight). Week of lactation was the next most important influence for all traits, except for fat and protein weight. In these 2 cases, calendar month of production was more important than week of lactation. Gestation effects accounted for less than $0.2 \%$ of the variation in all traits. Plots of weekly least square mean weights for each week of lactation (Figure 2) determined the shape of overall lactation curves for each component. These least square means were then used to investigate the overall characteristics of the lactation curve for each component, as well to test an alternative pattern of active cell numbers throughout lactation.

\section{Describing the Lactation Curve of Milk Yield and Milk Constituents}

Model 7 was fitted to each of the 5 component lactation curves, plus milk weight, derived from the least rived from least square mean values for each week of lactation $(\mathrm{kg})$.

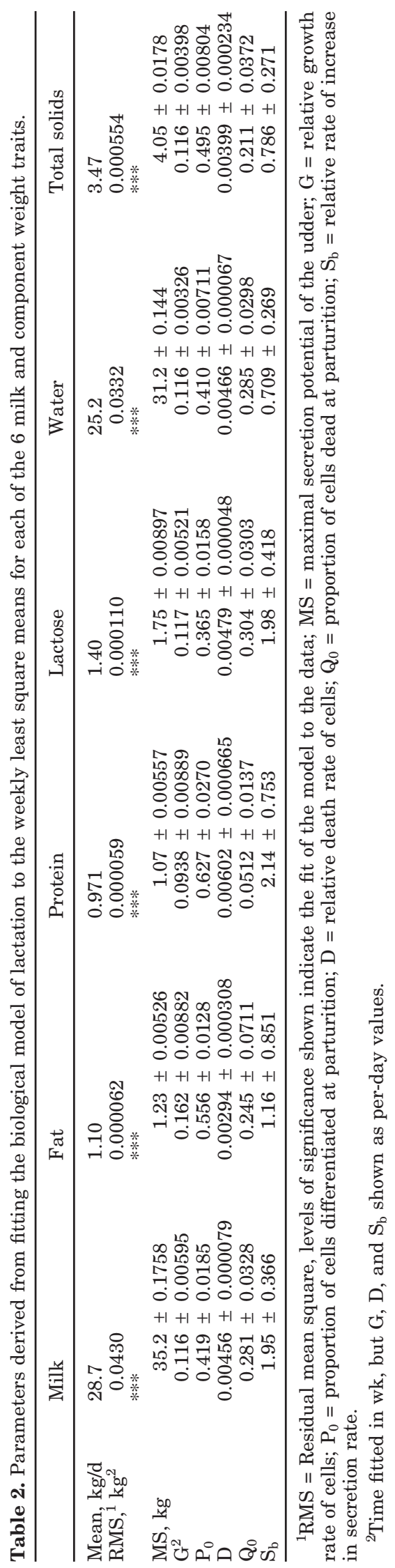

Journal of Dairy Science Vol. 87, No. 8, 2004 
Table 3. Calculated lactation curve characteristics from fitting the lactation model to the weekly least square means for each of the 6 milk and component weight traits.

\begin{tabular}{lcccccc}
\hline Parameter & Milk & Fat & Protein & Lactose & Water & Total solids \\
\hline Calculated total yield, kg & 8790 & 337 & 297 & 429 & 7743 & 1044 \\
Peak yield, kg & 33.4 & 1.20 & 1.05 & 1.66 & 29.6 & 3.88 \\
Day of peak yield & 47 & 35 & 56 & 47 & 46 & 45 \\
$\mathrm{GM}^{1}$, g/d & 423 & 13.4 & 5.17 & 24.0 & 386 & 40.9 \\
$\mathrm{DM}^{2}$, g/d & 38.8 & 0.787 & 0.587 & 2.07 & 35.4 & 3.86 \\
\hline
\end{tabular}

${ }^{1} \mathrm{GM}=$ Increase in daily production midway between the start and peak of lactation.

${ }^{2} \mathrm{DM}=$ Decrease in daily production midway between peak and the end of lactation.

square means as described above (Figure 2). The parameters derived are shown in Table 2 in addition to the average of the weekly least square means. Various characteristics of the lactation curves, calculated from model 7, are shown in Table 3. Maximal secretion potential of milk was $35.2 \mathrm{~kg} / \mathrm{d}$, with some $42 \%$ of secretory cells being differentiated at the start of lactation. Relative growth rates of secretory cell numbers was 0.116/ $\mathrm{d}$, with milk yield increasing by $423 \mathrm{~g} / \mathrm{d}$ midway between the start and peak of lactation. Milk yield peaked at $33.4 \mathrm{~kg}$ at $47 \mathrm{DIM}$ and declined thereafter with a relative "death" rate of 0.00456 . This loss in yield was $38.8 \mathrm{~g} / \mathrm{d}$ midway between peak and d 305. Total milk yield to d 305 was estimated to be $8790 \mathrm{~kg}$. Secretion rate had a relative growth rate of 1.95 and reached its maximum in the 2 nd wk of lactation.

Lactation curves of the 5 milk components also are described in Tables 2 and 3. Maximal secretion potential varied with the components ranging from water at $31.2 \mathrm{~kg} / \mathrm{d}$ to protein at $1.07 \mathrm{~kg} / \mathrm{d}$. Comparing the other curve parameters in Table 2 reveals a clear pattern. Water, milk, and lactose had largely similar values, but

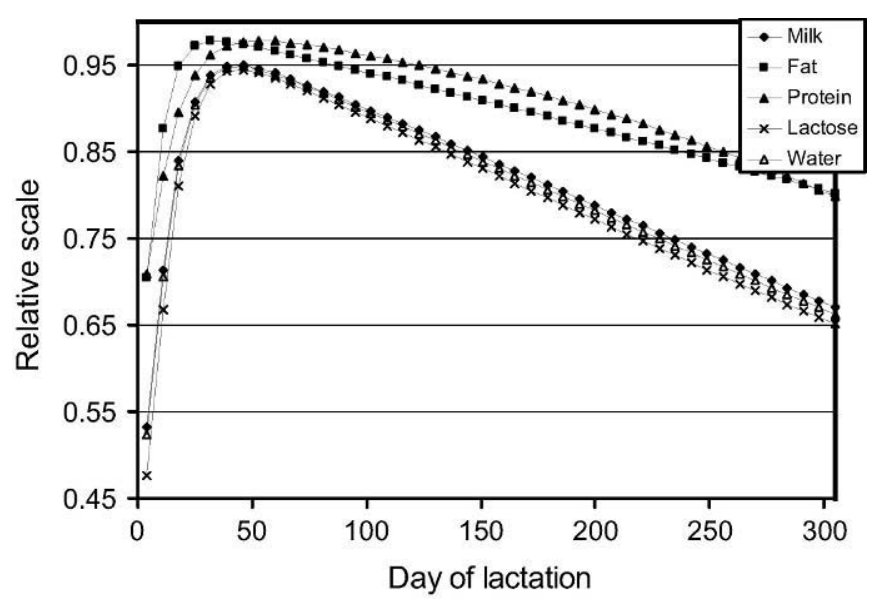

Figure 3. Comparative lactation curves for milk, fat, protein, lactose, and water derived from least square means, but omitting secretion rate scaling factor. (Relative scale $=$ milk or component weight relative to the maximal secretion potential of that component). differed considerably from both fat and protein. These similarities also were reflected in the value for day of peak yield (Table 3 ). Total solids had values intermediate between fat, protein, and lactose, as expected.

Fat weight showed a much faster increase in early lactation, with a peak at $\mathrm{d} 35$, and a slower decrease postpeak (Table 2) than any other component. Protein had the slowest prepeak increase and peaked later, on d 56. Protein production also declined more quickly in later lactation than any other trait.

Comparable changes in the 6 lactation curves are illustrated in Figure 3, which were derived from model 2 , omitting the maximal secretion potential of the udder (MS) and the secretion rate term $\left(S_{F}\right.$, etc.). Total milk yield, water weight, and lactose had almost identical curves, except for a slightly quicker decline in later lactation for lactose. Fat and protein increased faster in early lactation and declined slower in late lactation than remaining components. Total solids curve (not shown) was the mean of fat, protein, and lactose, as expected.

\section{Secretion Rate of Milk and its Components}

Pattern of secretion per cell for each milk component, calculated using model 8 with a maximal cell number of $2.8 \times 10^{10}$, is shown in Figure 4. The curves fell into 3 patterns. Fat, protein, and total solids (not shown) were secreted at their highest rate at the start of lactation, and then declined until between $\mathrm{d} 30$ and 60 , when they started to gradually increase again until the (artificial) end of lactation at d 305. Secretion of water followed a pattern similar to that of milk yield, being secreted at an almost constant rate throughout lactation. A 3rd pattern was found for lactose, which increased in early lactation and then remained constant until near the end of lactation when it dropped slightly.

\section{Individual Lactations}

The result of fitting model 9 to 461 first-lactation testday milk yield data is shown in Table 4. Parameters associated with the prepeak phase of lactation were 

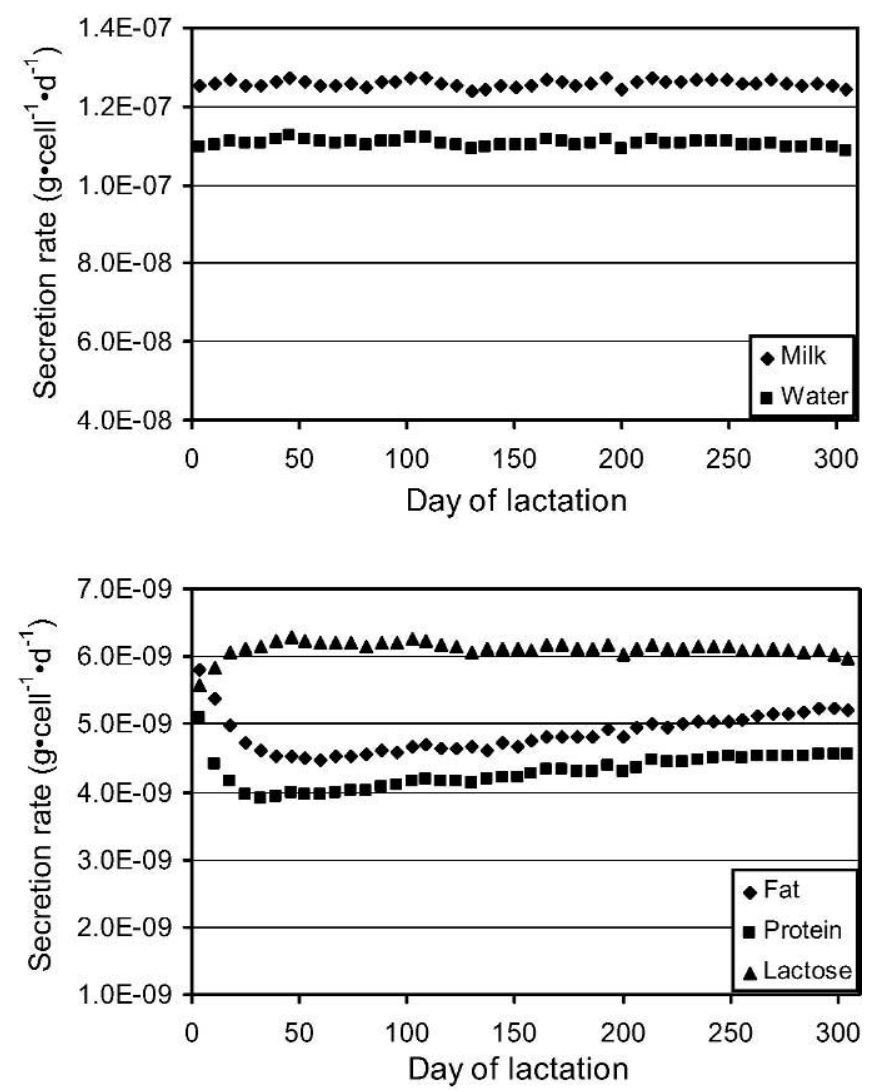

Figure 4. Secretion rate curves for the 5 components from overall least square means, assuming a constant milk secretion rate throughout lactation and maximal number of secretory cells $=2.8 \times 10^{10}$.

highly variable, with coefficients of variation greater than $73 \%$. Remaining parameters were less variable, with maximal secretion potential of the udder having a low coefficient of variation $(<13 \%)$.

Means, standard deviations, and coefficients of variation for fat, protein, lactose, and water secretion rates, calculated for each lactation using model 4 , are shown in Table 5. In these analyses milk secretion rate was calculated as the maximal secretion potential $/(2.8 \times$ $10^{10}$ ), where the maximal secretion potential was de-

Table 4. Means and standard deviations of lactation curve parameters from fitting the lactation model to the 461 lactations for milk weight.

\begin{tabular}{lllc}
\hline Parameter & Mean & SD & CV (\%) \\
\hline $\mathrm{MS},{ }^{1} \mathrm{~kg}$ & 34.8 & 4.27 & 12.3 \\
$\mathrm{G}^{2}$ & 1.27 & 1.75 & 137 \\
$\mathrm{P}_{0}$ & 0.342 & 0.252 & 73.7 \\
$\mathrm{D}$ & 0.00713 & 0.00195 & 27.3 \\
\hline
\end{tabular}

${ }^{1} \mathrm{MS}=$ Maximal secretion potential of the udder; $\mathrm{G}=$ relative growth rate of cells; $\mathrm{P}_{0}=$ proportion of cells differentiated at parturition; $\mathrm{D}=$ relative death rate of cells.

${ }^{2}$ Time fitted in wk. rived from the model 9 analyses, described above, for each lactation. Fat secretion rate was the most variable, whereas the other 3 secretion rates had similar coefficients of variation. The patterns of weekly unadjusted means for fat, protein, and lactose secretion rates (not shown) were similar to those shown for the overall lactation curves in Figure 4. Weekly coefficients of variation for the 4 secretion rate traits are shown in Figure 5 . Not only was fat secretion rate the most variable trait overall, but it also had a much greater spread of weekly coefficients of variation as well. Fat secretion rate was highly variable at the beginning of lactation, became less so by approximately wk 10, but ranged between 0.16 and 0.18 until the end of lactation. This contrasts considerably with lactose and water secretion rates. Not only did these 2 traits have identical coefficients of variation, but their values were also similar throughout lactation. Protein secretion rate was the least variable of all the 4 traits until near the end of lactation.

Results of fitting a GLM (model 6) to each secretion rate trait for each cow are also summarized in Table 5 . Effects of cow, week of lactation, and month of production were highly significant on all traits. The model explained over $80 \%$ of the variation in water and lactose secretion $\left(\mathrm{R}^{2}>0.80\right)$ and accounted for a high proportion of the variation in protein secretion $\left(\mathrm{R}^{2}=0.76\right)$. The lower value for fat secretion rate indicated that other sources of variation in fat secretion were not accounted for by the model. Effect of individual cow contributed most to the variation in all 4 traits. Other significant effects contributed to less than $1 \%$ of the variation in lactose and water secretion rates, whereas for fat and protein, they contributed up to 5\%. Month of production had little effect on secretion rates in any trait. Gestation had no effect on secretion rates (Table 5).

Correlations among the 4 secretion rates are shown in Table 6. Correlations of unadjusted values showed a strong relationship among all the secretion rate variables, ranging from 0.52 (fat with lactose) to 0.97 (water with lactose). In contrast, when effects of individual cows were removed, correlations were all reduced; the largest reduction was in the correlation between lactose and protein and the smallest reduction being between lactose and water (0.97 to 0.94$)$. Considering withincow correlations, lactose and water secretion rates were highly correlated (0.94) and the correlations involving protein secretion rate and both water and fat were about 0.65 . Fat secretion rate had the lowest correlations at 0.31 (with lactose) and 0.38 (with water). These correlations largely reflect the relationship between the secretion rate values as they varied throughout lactation, as shown by the various lactation curves. When week of lactation was removed, the correlations all be- 
Table 5. Means, standard deviations, coefficients of variation, and proportions of variation accounted for in the secretion rate traits using 16,193 test-day records from 461 first-lactation cows.

\begin{tabular}{lcccc}
\hline Secretion rate $^{1}$ & Fat & Protein & Lactose & Water \\
\hline Mean, g/d $\times 10^{8}$ & 5.00 & 4.21 & 6.04 & 10.9 \\
SD, g/d $\times 10^{9}$ & 8.93 & 6.71 & 9.57 & 174 \\
CV, $\%$ & 17.8 & 15.9 & 15.9 & 15.9 \\
$\mathrm{R}^{2}$ & 0.64 & 0.76 & 0.81 & 0.83 \\
Variance proportion & & & $0.734^{* * *}$ & $0.754^{* * * *}$ \\
Cow & $0.489^{* * *}$ & $0.605^{* * *}$ & $0.007^{* * *}$ & $0.002^{* * * *}$ \\
Week of lactation & $0.048^{* * *}$ & $0.020^{* * *}$ & $0.003^{* * *}$ & $0.003^{* * * *}$ \\
Month of production & $<0.001^{* * *}$ & $0.003^{* * *}$ & $\mathrm{NS}$ & $\mathrm{NS}$ \\
Gestation & $\mathrm{NS}$ & $\mathrm{NS}$ & & \\
\hline
\end{tabular}

$* * * P<0.001$.

${ }^{1}$ Secretion rate values are quoted assuming $\mathrm{N}=2.8 \times 10^{10}$ after Vetharaniam et al. (2003). $\mathrm{N}$ is the total number of secretory cells that become active during lactation and is constant for any given lactation.

came larger than the within-cow estimates, with the exception of that between protein and fat.

\section{Secretion Rates and Alternative Patterns of Active Cells}

The pattern of milk secretion per cell throughout lactation is largely unknown and a pattern, based on comments by Knight et al. (1998), has been used until more accurate knowledge of milk secretion can be obtained. If future research finds that secretion rate of milk follows a pattern different from that assumed in model 1 , then the pattern of the milk components would change as well. This is illustrated in Figure 6 for fat, protein, and lactose secretion rates, with an alternative pattern of active cell numbers. This alternative pattern of active cell numbers follows the suggestion of Vetharaniam et al. (2003), with most cells becoming active at the start of lactation and secretion rates being reduced in early lactation due to lower levels of available energy. The result of fitting this alternative model was to change the calculated secretion rates from those shown in Figure 4.

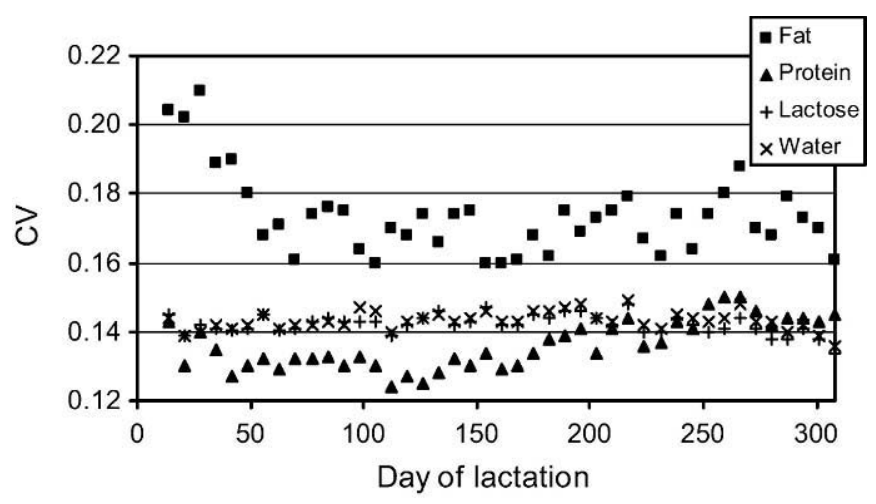

Figure 5. Weekly coefficients of variation for fat, protein, lactose, and water secretion rates per cell throughout lactation.

\section{DISCUSSION}

\section{The Biological Model Applied to Milk Components}

This article develops the biological model of lactation proposed by Pollott (2000) and applies it to production of the individual milk components, fat, protein, lactose, and water, throughout lactation. The biological model describes milk production in terms of 3 different aspects of mammary biology: cell differentiation, cell death, and the secretion rate of individual cells. The biological model of lactation has been extended to individual milk constituents by interpreting the last term in the model as the secretion rate of the individual milk components per cell (model 2) rather than that of milk as a whole, as in the original model. Although many authors have described milk production to comprise 2 components, the number of active secretory cells and the secretion rate per cell (Dijkstra et al., 1997), milk composition is usually discussed in terms of proportions rather than secretion rates. In this approach, the effect of changes in cell numbers is separated from that of component secretion rates and allows for investigation of milk component production as a cellular process.

The "milk-component biological model" takes no account of the causes of changes in milk composition throughout lactation, but does provide a mechanism for interpreting milk constituent production in a biologically understandable way. Model 3 demonstrates how the biological model relates to currently used measures of milk composition, namely proportions of fat, protein, and lactose. Model 4 uses this relationship to show how secretion rate per cell of individual milk constituents is directly related to the proportion value and rate of milk secretion itself. Although this is a traditional view of milk production, model 5 shows how milk could be thought of as the sum of secretion rates of the various milk components: fat, protein, lactose, and water. Clearly this may be extended to include various vita- 
Table 6. Overall (above the diagonal) and within cow (below the diagonal) correlations among milk component secretion rates. Effect of removing the effect of week of lactation shown in parentheses.

\begin{tabular}{lcccc}
\hline Item & Fat & Protein & Lactose & Water \\
\hline Fat & & $0.73 \pm 0.0037$ & $0.52 \pm 0.0057$ & $0.55 \pm 0.0055$ \\
Protein & $0.63 \pm 0.0048$ & & $0.80 \pm 0.0029$ & $0.81 \pm 0.0028$ \\
& $(0.53 \pm 0.0058)$ & $0.59 \pm 0.0052$ & & \\
Lactose & $0.31 \pm 0.0072$ & $(0.80 \pm 0.0028)$ & & $0.97 \pm 0.0004$ \\
& $(0.44 \pm 0.0064)$ & $0.66 \pm 0.0045$ & $0.94 \pm 0.0009$ & \\
Water & $0.38 \pm 0.0069$ & $(0.82 \pm 0.0026)$ & $(0.95 \pm 0.0008)$ & \\
& $(0.45 \pm 0.0064)$ & & \\
\hline
\end{tabular}

mins and minerals, or specific fats or proteins, in the same way. This approach can accommodate any new information that may become available on the factors that independently influence milk component production or cell numbers throughout lactation.

The approach developed in this paper has not overcome the major practical drawback in the application of the biological model of lactation: namely, the ability to measure active cell numbers, cell deaths, and secretion rate in practice. Measurement of any 2 of the 3 would be a significant advance. Until that is possible, and to use these new equations, it is necessary to use whatever limited information is available about the shapes of the 3 curves: cell proliferation, apoptosis, and secretion rate.

\section{Modeling Different Patterns of Active Cells}

Recent work has helped to improve understanding of how processes affecting milk production change during lactation. Vetharaniam et al. (2003) developed a mechanistic model of lactation that not only incorporated the production and death of cells, but also included energy availability to the udder as a factor influencing milk

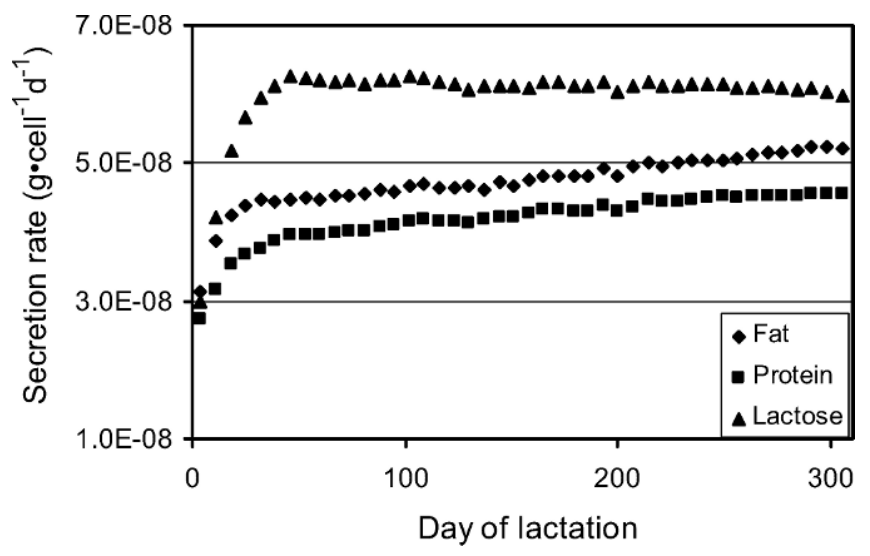

Figure 6. Effect on secretion rate of an alternative pattern for active cell numbers during lactation suggested by Vetharaniam et al. (2003). secretion. Results of their model imply that energy deficiency is a major factor limiting milk production in early lactation, despite the production of enough cells to give high milk yield from near the start of lactation. They suggest that most cells are differentiated soon after parturition, and secretion rate, rather than active cell numbers, determines early lactation milk yield. This contrasts with the assumption made in the original biological model (Pollott, 2000), based on comments by Knight et al. (1998), about the shape of the secretion rate curve and cell production early in lactation.

Use of the Vetharaniam et al. (2003) pattern of cell numbers resulted in fat secretion rate per cell rising sharply in early lactation up to about 50 DIM and then rising more gradually until the end of lactation (Figure 6 ). This contrasted with the original pattern, which fell from parturition to about 50 DIM and then rose gradually until the end of lactation (Figure 4). Protein secretion rate per cell followed a similar pattern to fat, but with a less steep rise in early lactation. Lactose secretion rate per cell also rose sharply in early lactation, but then remained constant throughout the remainder of the lactation under the Vetharaniam et al. (2003) pattern of cell production. This was similar to the lactose secretion rate pattern under the original model, but the rise was steeper in early lactation under the new model. These alternative patterns of fat, protein, and lactose secretion rates per cell are illustrative only and will eventually be more accurately defined once secretory cell number changes during lactation can be measured in practice.

In its current form, model 4 expresses the weight of a milk component produced per cell per day relative to that of milk, assuming that the pattern of cell differentiation, cell death, and milk secretion is as shown in model 1. Should the pattern of milk secretion subsequently be found to differ, as suggested above, from that assumed in model 1 , then the pattern of all other components derived using model 1 will change, but models 3 and 4 will still be useful for deriving these alternative patterns. If the pattern of active cell numbers and secretion rates suggested by Vetharaniam et al. (2003) were to be substantiated by further research, 
then model 1 could accommodate this new pattern by fixing the proportion of active cells differentiated at the start of lactation at a suitable value (say between 0.9 and 0.99). Alternatively, the number of differentiated parenchyma cells could be replaced with the total number of parenchyma cells that become active during lactation, effectively making the lactation curve dependent on just the apoptosis term and secretion rate. Vetharaniam et al. (2003) also suggested that energy supply to the udder might also determine milk production in late lactation under certain circumstances, particularly in animals on a low plane of nutrition. If this too were substantiated by further research, then milk offtake rate might need to be represented by a more complex term to allow a decrease in later lactation.

\section{Pattern of Component Production and Secretion Rates Throughout Lactation}

The pattern of milk component production throughout lactation is well known and has been extensively documented (see review by Rook, 1961a,b). Past work has used both the absolute weight of components produced and their proportions to describe changes in milk composition throughout lactation. In this report, separation of cell secretion rate from cell number allows the description of milk component secretion independently from that of milk as a whole. This approach results in the description of production of a milk component in terms of the absolute quantity per cell per day rather than as a proportion of milk production. Until it is possible to separate cell numbers from secretion rate in practice, pattern of secretion rates will depend on assumptions made about cell numbers (and vice versa). Once this becomes possible, then secretion rate patterns will change from those reported herein, although their relative values will not change.

\section{Factors Affecting Milk Component Production}

Variation among individual cows in the production of both milk and its constituents was the factor with the greatest effect in this research. Considering that cows used in this study were contemporaries in a single herd and managed in a similar way, then the differences between them were because of inherent factors within the cows themselves. These include the genetics of individual cows, their health status, rearing history, individual management, etc. In the context of this study, it also reflects differences in the number of active secretory cells, apoptosis rates, and secretion rate of individual cows for each milk component. As may be expected, effects of various factors studied were similar for water and milk production. A similarity existed between these
2 factors and lactose production. Fat and protein differed from the other 3 and from each other.

In contrast, week of lactation (the traditional lactation curve) had a relatively small effect on the variation in milk production and that of its constituents. This implies that although manipulation of the lactation curve may have some attractions under certain circumstances, it will not have such a large impact on milk production as choosing the "right" cows as replacements in the herd and managing them optimally.

The month in which the test-day records were collected had a small effect on production. This may not be surprising considering that the cows were housed all year and fed a TMR. Monthly variation would result from climatic changes experienced within the housing and changes in the nutritional quality of the TMR fed. Month of test-day record seemed to affect the protein composition of milk more than any other factor.

Effect of gestation on milk yield is well documented (Auran, 1974; Olori et al., 1997; Pollott, 2000). If this is mediated through an increase in cell death rate, then it is likely that milk component production also would decrease. Results presented in Table 5 indicate that secretion rate is unaffected by gestation, hence reduction in milk production as gestation advances must be due to a drop in active cell numbers.

\section{Factors Affecting Secretion Rates}

Variation in the 4 component secretion rates was largely determined by differences among cows. Gestation did not affect any of the rates and month of production had a very small effect. Effect of week of lactation on secretion rates was small, but greater for fat and protein than for lactose and water. The effect on these last 2 components was almost negligible.

Because availability of energy in excess of other requirements of the animal is a key determinant of fat production, fluctuating energy supply is likely to be a major determinant of fat secretion rate. This variation is associated with changes in the nutritional supply to the udder, independent of week of lactation.

Protein secretion was largely dependent on aspects of the individual cow herself. Even more striking was the almost total explanation of lactose and water secretion rates by the model and almost all the variation being explained by the individual cow factor. In fact, lactose and water secretion rates were almost perfectly correlated.

\section{Drivers of Milk Production}

Model 5 describes milk production as the sum of 4 independent secretion rates and cell numbers. Bio- 
chemical pathways for lactose, fat, and protein synthesis in the mammary gland have been well documented (Larson, 1985). Relationships among the 4 secretion rates (fat, protein, lactose, and water) estimated herein can be explained, to some extent, by these biochemical pathways. Energy is required to drive all biochemical changes, but in addition, glucose is the main precursor of lactose. Formation of lactose has priority over glucose supply. Surplus glucose and acetate are used to drive fatty acid synthesis, which supplements fatty acids of dietary and blood origin. Protein synthesis is a complex process that fundamentally relies on energy and AA supply to the mammary gland. Thus, if fat, protein, and lactose are all dependent on energy supply in the form of glucose, and lactose has priority and a constant secretion rate, then secretion of fat and protein must depend on surplus energy plus other factors. Fat and protein synthesis relies on the supply of other precursors that may be limiting in a different way from energy. Patterns of fat and protein secretion are similar and highly correlated, reflecting the common link of excess energy over that required by lactose synthesis.

Clearly, water is the major constituent of milk and so milk yield is primarily determined by water yield. However, water enters the mammary cells in an osmotic response to lactose and the soluble ions ( $\mathrm{Na}$ and $\mathrm{K})$ in cells (Larson, 1985). Thus, lactose production in the mammary gland is the major driver of milk production. This is borne out by the high correlation between lactose and water production (0.97) calculated from the unadjusted secretion rate values (Table 6). When the effect of cow, and then cow and week together, were removed from the model, the correlation between lactose and water was virtually unaffected. This implies that the link between water and lactose production is not related to factors associated with individual cows or stage of lactation. Further evidence for this is seen from the almost constant secretion rate of lactose and water throughout lactation (Figure 4), possibly only differing in the first 2 wk of lactation because of an overall limiting supply of energy. Clearly, lactose formation in secretory cells is a characteristic of individual cows, and variation among cows exists for this key aspect of milk production.

Glucose is the precursor of lactose and is a major circulating carbohydrate source in blood (Larson, 1985). Hence, level of energy available to the mammary gland in the form of glucose is likely to be a major determinant of milk production, and factors that affect glucose availability are the key influences on milk production. Concentrations of critical hormones as determined genetically and developmental history are likely to influence ability of the cow to switch glucose utilization to the mammary gland.
Production of fat in milk is mainly a function of the concentrations of fatty acids available to the mammary gland, with some contribution from glucose and acetate to form glycerol (Larson, 1985). Supply of fatty acids varies in response to a range of factors (Sutton, 1989), and fat secretion was the component with the most variable secretion rate. The common link with energy may explain the moderate level of correlation between fat and lactose ( 0.44 after accounting for cow and week of lactation), but fat secretion also was related to protein production (0.53).

Concentrations of AA available to the mammary gland largely determine protein production, with some contribution from acetate and the energy required to drive metabolic processes. Protein secretion rate was more highly related to lactose secretion than fat, but fat and protein secretion were also closely linked, probably via their use of excess energy available during lactation.

This approach to describing the way milk components are produced during lactation, and particularly model 5 , opens up an interesting perspective on daily milk production. Daily milk production by a dairy animal is a combination of 6 biological elements: the number of secretory cells produced up to that day of the lactation, the number of these cells that have died by apoptosis, and secretion rates per cell of the 4 components (fat, protein, water, and lactose) on that day. Given the proportions of these 4 components in milk, it is really only water that is of interest because it comprises approximately $88 \%$ of milk yield. However, water content of milk is "controlled" by the amount of lactose (and some other ions) secreted, and so the major determinant of milk yield is effectively the secretion rate of lactose combined with the number of active cells. Clearly, fat and protein are important in terms of nutrition of the consumer of milk, but contribute little to variation in milk yield. Thus, milk production is largely determined by the secretion rate of lactose in the mammary gland, the number of secretory cells that the dairy animal produces and, to a lesser extent, factors influencing apoptosis of secretory cells. Developing this approach further indicates that high-yielding dairy cows will be large and thin. They will be large because growth hormone is likely to affect cell numbers in the mammary gland as well as body size. They will be thin because high-yielding cows maximize the supply of lactose precursors to the mammary gland (i.e., maximize energy partitioning in favor of the udder) perhaps to the detriment of other processes that require a good energy supply at the same time.

\section{CONCLUSIONS}

This article has described the way that a biological model of lactation, used initially to describe milk pro- 
duction, can be extended to characteristics of milk composition. Proportions of fat, protein, lactose, water, and total solids can be described in terms of the number of active secretory cells and the secretion rate per cell. In this case, the secretion rate per cell was the amount of each component secreted per cell, per day. The pattern of secretion for each component was heavily dependent on the pattern of secretory cell numbers assumed in the model. Two alternative patterns were tested and the secretion rate per cell for the milk components described throughout lactation compared. Analysis of 461 lactations demonstrated that a range of factors influenced production of milk components. Week of lactation, month of production, pregnancy status, and the individual cow all affected production of the milk components studied. All these factors, except pregnancy, also were found to affect secretion rates per cell of the milk components. This approach to describing the production of milk components during lactation will become more widely applicable once it becomes possible to separate the effects of active cell numbers from the secretion rate of milk per cell per day.

\section{ACKNOWLEDGMENTS}

B. McGuirk supplied the data used in this study from the dataset analyzed by V. Olori for his Ph.D. study at Edinburgh University. Both are gratefully acknowledged for their contribution to this research.

\section{REFERENCES}

Auran, T. 1974. Studies on monthly and cumulative monthly milk yield records II. The effect of calving interval and stage of pregnancy. Acta Agric. Scand. 24:339-348.
Dijkstra, J., J. France, M. S. Dhanoa, J. A. Maas, M. D. Hanigan, A. J. Rook, and D. E. Beever. 1997. A model to describe growth patterns of the mammary gland during pregnancy and lactation. J. Dairy Sci. 80:2340-2354.

Gootwine, E., and G. E. Pollott. 2000. Factors affecting milk production in improved Awassi ewes. Anim. Sci. 71:607-615.

Knight, C. H., M. Peaker, and C. J. Wilde. 1998. Local control of mammary development and function. Rev. Reprod. 3:104-112.

Larson, B. L. 1985. Lactation. Iowa State Univ. Press, Ames.

Olori, V. E., S. Brotherstone, W. G. Hill, and B. J. McGuirk. 1997. Effect of gestation stage on milk yield and composition in Holstein-Friesian cattle. Livest. Prod. Sci. 52:167-176.

Olori,V. E., S. Brotherstone, W. G. Hill, and B. J. McGuirk. 1999a. Fit of standard models of the lactation curve to weekly records of milk production of cows in a single herd. Livest. Prod. Sci. 58:55-63.

Olori, V. E., W. G. Hill, B. J. McGuirk, and S. Brotherstone. 1999b. Estimating variance components for test day milk records by restricted maximum likelihood with a random regression animal model. Livest. Prod. Sci. 61:53-63.

Pollott, G. E. 2000. A biological approach to lactation curve analysis for milk yield. J. Dairy Sci. 83:2448-2458.

Pollott, G. E., and E. Gootwine. 2000. Appropriate mathematical models for describing the complete lactation of dairy sheep. Anim. Sci. 71:197-207.

Pollott, G. E., and E. Gootwine. 2001. A genetic analysis of complete lactation milk production in improved Awassi sheep. Livest. Prod. Sci. 71:37-47.

Rook, J. A. F. 1961a. Variations in the chemical composition of the milk of the cow-Part 1. Dairy Sci. Abstr. 23:251-258.

Rook, J. A. F. 1961b. Variations in the chemical composition of the milk of the cow-Part 2. Dairy Sci. Abstr. 23:303-308.

SAS. 1989. SAS/STAT User's Guide. Version 6. 4th ed. Vol. 2. GLMVARCOMP. SAS Inst., Inc., Cary, NC.

Strathie, R. J., and B. J. McGuirk. 1995. Developments with the MOET dairy breeding scheme. Br. Cattle Breed. Club. 50:9-15.

Sutton, J. D. 1989. Altering milk composition by feeding. J. Dairy Sci. 72:2801-2814.

Tow, G. J. 1984. The effect of the compositional quality of milk on new product development. Pages 11-15 in Milk Compositional Quality and Its Importance in Future Markets. Occ. Pub. No. 9, Br. Soc. of Anim. Prod., Edinburgh, UK.

Vetharaniam, I., S. R. Davis, T. K. Soboleva, P. R. Shorten, and G. C. Wake. 2003. Modeling the interaction of milking frequency and nutrition in mammary gland growth and lactation. J. Dairy Sci. 86:1987-1996. 